\title{
In Vitro Variation of Drought Tolerance in Five Actinidia Species
}

\author{
Yun-Peng Zhong, Zhi Li, Dan-Feng Bai, Xiu-Juan Qi, Jin-Yong Chen, Cui-Guo Wei, \\ Miao-Miao Lin, and Jin-Bao Fang ${ }^{1}$ \\ Key Laboratory for Fruit Tree Growth, Development and Quality Control, Zhengzhou Fruit Research \\ Institute, Chinese Academy of Agricultural Sciences, Zhengzhou 450009, China
}

\begin{abstract}
AdDitional INDEX WORDs. growth and physiological response, tissue culture, principal component analysis
Abstract. To select resistant germplasm resources and understand the growth and physiological responses of kiwifruit (Actinidia sp.) to drought stress, five species, Actinidia macrosperma (Acma), Actinidia longicarpa (Aclo), Actinidia deliciosa (Acde), Actinidia hemsleyana (Ache), and Actinidia valvata (Acva), were assessed under tissue culture conditions. Rootless seedlings of five species were cultured in a medium containing polyethylene glycol [PEG (formula weight 8000$)]$ to induce drought stress $(0 \%, 5 \%, 10 \%, 15 \%$, and $20 \%)$. After a 30-day culture, three growth indices [fresh weight (FW), plant height (PLH), and leaf number (LN)] and six physiological indices were determined, and the drought damage index (DDI) was determined. The DDIs of five species increased, and three growth indices decreased with increasing PEG concentrations. The following changes were observed under $20 \%$ PEG treatment conditions: superoxide dismutase (SOD) activities increased significantly in Acma, Aclo, and Ache specimens; peroxidase (POX) activities remained stable in Acde, Ache, and Acva specimens; and catalase (CAT) activities increased sharply in Acma and Acva. Furthermore, the results indicated that soluble sugar (SS) content increased slightly in Acma, Aclo, Acde, and Ache but it decreased in Acva specimens. Proline (PRO) content increased significantly in Acma and Acva, and malondialdehyde (MDA) contents tended to increase under drought stress in all five species. Principal component analysis (PCA) results indicated that the order of drought tolerance in the five genotypes examined in this study under tissue culture conditions was as follows: Acma $>$ Acva $>$ Acde $>$ Aclo $>$ Ache. Therefore, we concluded that Acma and Acva are more resilient germplasm resources that represent promising kiwifruit-breeding materials. Furthermore, tolerance to drought stress in these species should be further investigated under orchard conditions.
\end{abstract}

Of all the environmental stresses, drought has the greatest adverse effect on plant growth and development, leading to extensive losses in productivity (Ciais et al., 2005). The susceptibility of individual plants to drought stress depends on both the plant (e.g., its genotype; growth phase; and structural, morphophysiological, and biochemical adaptations to water deficits) and the degree of environmental stress (e.g., duration and intensity of soil and atmospheric water deficits) (Fleta-Soriano and Munne-Bosch, 2016; Zeppel et al., 2015). Forecasts predict that global warming will expand droughtaffected areas worldwide. More importantly, global warming will increase the number of areas potentially exposed to severe drought over the next few decades in response to increased temperatures of between 1.4 and $5.8^{\circ} \mathrm{C}$ by the end of the $21 \mathrm{st}$ century (Salinger, 2005). Plants rapidly adjust their structure and metabolism to withstand drought stress. Based on the mechanism of drought tolerance, plant strategies can be divided into four categories: drought avoidance, drought escape, drought tolerance, and drought recovery (Fang and Xiong, 2015), with drought avoidance and drought tolerance being the two major strategies. Drought avoidance is the maintenance of key physiological processes such as stomata regulation and root system development during moderate drought conditions. Drought tolerance is the ability of plants to withstand severe

Received for publication 22 Mar. 2018. Accepted for publication 30 May 2018. This research was supported by the Agricultural Science and Technology Innovation Program (CAAS-ASTIP-2017-ZFRI), Central Public-interest Scientific Institution Basal Research Fund, ZFRI, CAAS (1610192017708), and Modern Agricultural Industry Technology of Henan Province (S2014-11).

${ }^{1}$ Corresponding author. E-mail: fangjinbao@caas.cn. dehydration through specific physiological activities such as osmotic adjustment via osmoprotectants (Luo, 2010). Drought escape is the ability of plants to adjust their growth period or lifecycle like some cotton (Gossypium hirsutum) cultivars that exhibit short life cycles to avoid seasonal droughts (Manavalan et al., 2009). Moreover, drought recovery is the ability of plants to resume growth and yield after exposure to severe drought stress (Ullah et al., 2017).

Drought is a major threat to kiwifruit in the early summer in northern China, especially when extreme weather occurs during the early 6-7 weeks after a full bloom because most fruit expand at this stage (Gallego et al., 1997). Reduced water availability seriously compromises fruit growth and development (Torres-Ruiz et al., 2016), and drought causes the wilting . Furthermore, drought reduces respiration and photosynthesis, and it seriously affects the translocation and distribution of assimilates and the accumulation of nutrients. These changes initially lead to decreased fruit production and quality because the reproductive tissues are more affected by drought stress than vegetative tissues (Barnabas et al., 2008; Zandalinas et al., 2017). If drought conditions are sustained for a prolonged time, the detrimental effects become irreversible, resulting in the dehydration of branches and vines and even death of the whole plant (Tramontini et al., 2013).

According to the new taxonomic revision, the genus Actinidia contains 75 taxa, including 54 species and 21 botanical varieties, and most of the existing kiwifruit cultivars are developed from four species: $A$. chinensis, A. deliciosa, $A$. arguta, and $A$. eriantha, with high representation by the first two taxa (Ferguson and Huang, 2007; Li et al., 2014). More than 100 cultivars were released in China, New Zealand, 
Italy, Chile, and South Korea, but screening of resistant germplasm resources and rootstock kiwifruit breeding do not garner as much attention as the scions, leading to limited reports about kiwifruit rootstock screening. Cruz-Castillo reports the influence of nine different rootstocks on the growth of 'Hayward' kiwifruit 4-5 years after grafting. Three rootstocks improved the yield of large-sized fruit, and plants grafted on rootstock 4 (male) were characterized by strong trunk growth and large fruit size over three seasons. By contrast, scions on female rootstocks 7 and 9 were less productive in the second and third seasons. Ungrafted ownrooted vines exhibited high yield in two seasons. As a scion 'Hayward' A achieved the best field performance in yield and fruit sizing across eight root systems in two seasons. Vines grafted with 'Hayward' B showed low productivity (CruzCastillo et al., 1991, 1997). One A. hemsleyana kiwifruit rootstock named 'Kaimai' was registered in New Zealand in the $1980 \mathrm{~s}$, and it was used as the flowering-promoting rootstock for 'Hayward' (Wang et al., 1994). Another named kiwifruit rootstock was 'Bounty 71'. When compared with the 'Bruno' rootstock, 'Bounty 71' rootstock promoted higher flower numbers and larger fruit sizes from the 'Hort16A' scion, thus, resulting in higher yields of export quality fruit and commercial levels of Pseudomonas syringae pv. actinidiae tolerance (Hawken, 2013).

In this study, to screen potential resistant resources for kiwifruit breeding or rootstock selection in future studies, the growth and physiological responses of five Actinidia species to PEG-induced drought stress under tissue culture conditions were measured, and the drought tolerance of each species was assessed.

\section{Materials and Methods}

Plant materials and drought treatments. Five Actinidia species, A. macrosperma (Acma), A. longicarpa (Aclo), A. deliciosa (cultivar Hayward, Acde), A. hemsleyana (Ache), and A. valvata (Acva), were collected during investigations of wild kiwifruit resources and were kept in the Zhengzhou Fruit Research Institute, Chinese Academy of Agricultural Sciences germplasm repository in Zhengzhou, China. Dormant shoot sections of the five kiwifruit species were collected in Winter 2014 and sprouted in a plastic container filled with water. The plants were kept in an air-conditioned room, and the water was changed regularly. New shoots, which sprouted from the shoot sections in Spring 2015, were cut off and used as explants. The explants were sterilized with $75 \%$ alcohol for $30 \mathrm{~s}$ and $0.1 \% \mathrm{HgCl}_{2}$ for $1 \mathrm{~min}$ and were then washed for five to six times using sterilized water. The sterilized explants were cut into $\approx 3$ to $5 \mathrm{~cm}$ lengths with about two to three buds using a sterilized blade. The dissections were transplanted into the following medium: Murashige and Skoog (MS) medium $+0.5 \mathrm{mg} \cdot \mathrm{L}^{-1}$ 6-benzylaminopurine $+1.0 \mathrm{mg} \cdot \mathrm{L}^{-1}$ indole-3-butytric acid [pH 5.8, 24 to $26{ }^{\circ} \mathrm{C}, 40 \%$ relative humidity, $14 / 10 \mathrm{~h}$ (light/dark)]. The sprouts were cut off and transplanted into a new medium (same as mentioned previously) to proliferate, and sterile rootless plantlets of the five species were obtained. PEG was added to the culture medium to induce drought stress as described previously (Gopal and Iwama, 2007), and five PEG concentrations $(0 \%, 5 \%, 10 \%$, $15 \%$, and $20 \%$ ) were used in this study. Plantlets with two to three leaves and stems $\approx 1 \mathrm{~cm}$ in height were used as experimental materials and were transplanted into the following basic propagation culture medium: $\mathrm{MS}+1.0 \mathrm{mg} \cdot \mathrm{L}^{-1}$ zeatin $+0.5 \mathrm{mg} \cdot \mathrm{L}^{-1}$ gibberellin A3 [pH 5.8, 14/10 h (light/dark)]. Each PEG treatment for each species contained 30 plantlets $(6.5 \times 10.5 \mathrm{~cm}$ culture bottles), and each plantlet was a replication.

Drought Damage index DEsign. A grade scale of the DDI was developed based on the different damage symptoms observed in leaves and shoots after $30 \mathrm{~d}$ of treatment. Preliminary experiment showed that $30 \mathrm{~d}$ was an appropriate period of stress. At this time point, the height of plantlets did not exceed the culture bottle, and the damage symptoms were distinct and easy to observe, with some plantlets almost completely dry under $20 \%$ PEG conditions. The grade scale was as follows: 1) healthy leaves and shoots with no damage symptom; 2) yellowing or browning leaf necrosis, mainly at leaf margins and tips areas; 3 ) dried leaves or petioles or some leaves watery; 4) leaves dried or abscised, or death of apical meristem and shoot (Fig. 1). The DDI value was calculated according to the following formula: $\mathrm{DDI}=\sum(X \times n) /(4 N) \times 100$, where $X$ represents the index of damage grade, $n$ is the number of each damage grade, and $N$ is the total number of examined seedlings.

Growth indicator MEASUREMENTS. After removing the medium, moisture on the plantlet surface was absorbed using absorbent paper, and FW, PLH (represented by the stem height), and LN were measured immediately.

AnTIOXIDANT ENZYMe aCtivities. For extraction of antioxidant enzymes, fresh leaves $(1 \mathrm{~g})$ in the middle parts of seedlings

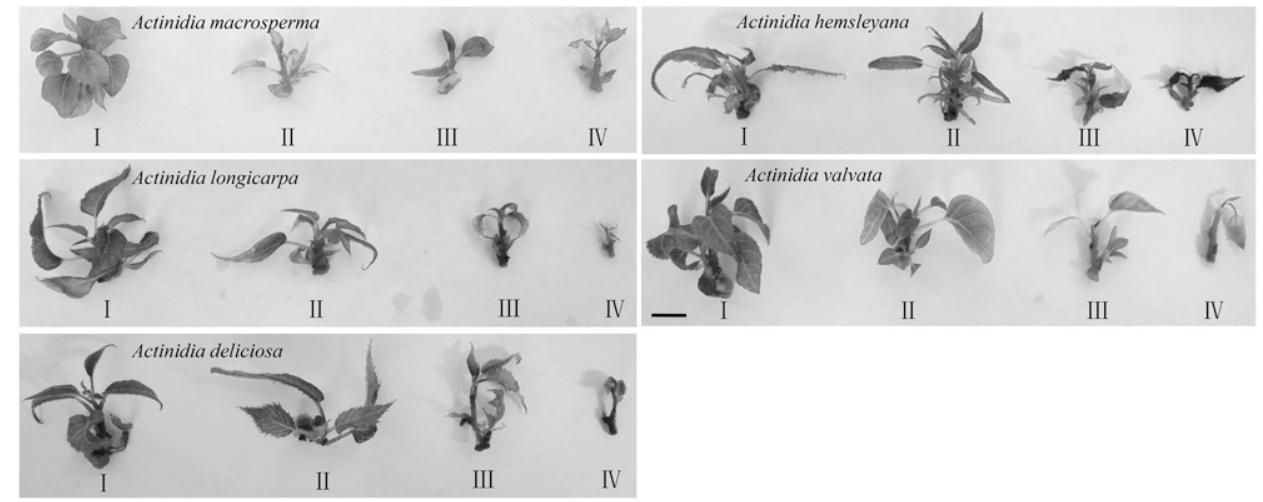

Fig. 1. Grade scale of the drought damage index (DDI) of five Actinidia species under drought stress. Sterile rootless plantlets, with two to three leaves and $\approx 1 \mathrm{~cm}$ height, of the five species were used in this study, and polyethylene glycol (formula weight 8000) was added to the medium [Murashige and Skoog medium +1.0 $\mathrm{mg} \cdot \mathrm{L}^{-1}$ zeatin $+0.5 \mathrm{mg} \cdot \mathrm{L}^{-1}$ gibberellin $\left.\mathrm{A} 3(\mathrm{pH} 5.8)\right]$ at different concentrations $(0 \%, 5 \%, 10 \%, 15 \%$, and $20 \%)$ to induce drought stress. After $30 \mathrm{~d}$ of treatment $\left(14 / 10 \mathrm{~h}\right.$ light/dark, 24 to $\left.26^{\circ} \mathrm{C}\right)$, typical damage symptoms observed in leaves and shoots were photographed, and the following DDI grade scale was developed: I = healthy leaves and shoots with no damage symptoms; II = yellowing or browning leaf necrosis, mainly at leaf margins and tips areas; III = dried leaves or petioles or some leaves watery; IV = leaves dried or abscised or death of apical meristem and shoot; $\mathrm{bar}=1 \mathrm{~cm}$. 
after $30 \mathrm{~d}$ of treatment were homogenized in $5 \mathrm{~mL}$ of $50 \mathrm{~mm}$ cooled phosphate buffer $(\mathrm{pH}$ 7.8) using a cold mortar and pestle. The homogenate was centrifuged at $4{ }^{\circ} \mathrm{C}$ for $30 \mathrm{~min}$ at $12,000 g_{\mathrm{n}}$, and the supernatant was used to determine the activities of SOD (EC 1.15.1.1), POX (EC 1.11.1.7), and CAT (EC 1.11.1.6). SOD activity was determined following the method of Giannopolitis and Ries (1977), which measured its ability to inhibit the photoreduction of nitroblue tetrazolium (NBT) to blue formazan by flavins under illumination. One unit of SOD activity was defined as the amount of enzyme that inhibited $50 \%$ of NBT photoreduction vs. a blank cell containing no enzymatic extract. CAT and POX activities were appraised using the method of Cakmak and Marschner (1992) with some modifications. The POX reaction solution $(3 \mathrm{~mL})$ contained $50 \mathrm{~mm}$ phosphate buffer (pH 5.0), $20 \mathrm{~mm}$ guaiacol, $40 \mathrm{mM} \mathrm{H}_{2} \mathrm{O}_{2}$, and $0.1 \mathrm{~mL}$ enzyme extract. POX activity was expressed as the change in absorbance of the reaction mixture at $470 \mathrm{~nm} \cdot \mathrm{mg} \cdot \mathrm{min}^{-1}$ of $\mathrm{FW}$. CAT reaction solution $(3 \mathrm{~mL})$ contained $50 \mathrm{~mm}$ phosphate buffer ( $\mathrm{pH} 7.0$ ), $5.9 \mathrm{~mm} \mathrm{H}_{2} \mathrm{O}_{2}$, and $0.1 \mathrm{~mL}$ enzyme extract. The reaction was started by adding the enzyme extract and changes in reaction solution absorbance (read at $240 \mathrm{~nm}$ every $20 \mathrm{~s}$ ). One unit CAT activity was defined as an absorbance change of 0.01 units per minute. All spectrophotometric analyses were conducted on a spectrophotometer (BioMate 3S; Thermo Fisher Scientific, Waltham, MA).

Measurement of osmoregulatory compounds. Soluble sugar content was measured using the anthrone-sulfuric acid method (Li et al., 2008). Fresh leaves $(0.5 \mathrm{~g})$ in the middle part of seedlings after $30 \mathrm{~d}$ of treatment were homogenized in $8 \mathrm{~mL}$ of deionized water and incubated in a boiling water bath for $30 \mathrm{~min}$. The extract was then filtered twice through $25 \mu \mathrm{m}$ Whatman filter paper (Sigma-Aldrich, Shanghai, China), and its volume was adjusted to a final volume of $25 \mathrm{~mL}$ in a volumetric flask. A $0.5-\mathrm{mL}$ aliquot of the filtrate was transferred to a test tube containing $1.5 \mathrm{~mL}$ of distilled water, and then, $5 \mathrm{~mL}$ of anthrone reagent was added before the mixture was placed in a boiling water bath for $10 \mathrm{~min}$. The absorbance of the mixture was measured at $630 \mathrm{~nm}$ after the solution was cooled to room temperature. SS concentrations were determined using a standard curve generated from the $\mathrm{A}_{630}$ of 0 to $100 \mathrm{mg} \cdot \mathrm{L}^{-1}$ of pure glucose, and values were calculated in terms of grams SS per gram $\mathrm{FW}$ at $25^{\circ} \mathrm{C}$.

Free PRO content was determined using the sulfosalicylic acid-ninhydrin reaction method (Bates et al., 1973). Fresh leaves $(0.2 \mathrm{~g})$ were extracted in $5 \mathrm{~mL}$ of $3 \%(\mathrm{w} / \mathrm{v})$ sulfosalicylic acid in a boiling water bath for $10 \mathrm{~min}$. After filtration, $2 \mathrm{~mL}$ of the supernatant was transferred to a tube containing $2 \mathrm{~mL}$ distilled water, $2 \mathrm{~mL}$ glacial acetic acid, and $4 \mathrm{~mL}$ acidified ninhydrin reagent. After 50 min of incubation in a boiling water bath, the samples were allowed to cool to room temperature before adding $4 \mathrm{~mL}$ of toluene to each tube, and samples were then placed on an orbital shaker (2000 rpm) to extract the colored product. The absorbance of the separated toluene layer was determined at $532 \mathrm{~nm}$. PRO concentrations were determined using a standard curve generated from $\mathrm{A}_{532}$ of 0-12 $\mathrm{mg} \cdot \mathrm{L}^{-1}$ pure PRO solution.

MalONALDEHYde CONTENT. The MDA content was measured using the thiobarbituric acid (TBA)-reactive metabolite method described by Shah et al. (2001). A 2-mL sample of crude extract was homogenized in $2 \mathrm{~mL} 0.5 \%(\mathrm{w} / \mathrm{v})$ TBA in $5 \%(\mathrm{w} / \mathrm{v})$ trichloroacetic acid. The mixture was incubated in a boiling water bath for $15 \mathrm{~min}$ and was then placed in an ice bath to cool. After cooling, the supernatant was centrifuged at $5000 g_{\mathrm{n}}$ for $10 \mathrm{~min}$ before supernatant absorption was recorded at $532 \mathrm{~nm}$, and nonspecific turbidity was corrected by subtracting the absorbance recorded at $600 \mathrm{~nm}$. The extent of lipid peroxidation was expressed in micromoles MDA per gram FW using an extinction coefficient of $155 \mathrm{~mm} \cdot \mathrm{cm}^{-1}$.

COMPREHENSIVE ASSESSMENT OF DROUGHT TOLERANCE. A comprehensive evaluation index was developed by combining cluster analyses with a SD coefficient allocation weighted method. The calculation of the evaluation index included the following steps:

1. Data standardization: A subordinator function was used to standardize the measured raw data for each parameter:

$$
\begin{aligned}
& \mu\left(X_{i j}\right)=\left(X_{i j}-X_{\min }\right) /\left(X_{\max }-X_{\min }\right), \\
& \mu\left(X_{i j}\right)=\left(X_{\max }-X_{i j}\right) /\left(X_{\max }-X_{\min }\right),
\end{aligned}
$$

where $X_{i j}$ is the value of the $j$ th variable of the $i$ th genotype, and $X_{\min }$ and $X_{\max }$ represent the minimal and the maximal value among the $X_{i j}$ values for the $j$ th variable, respectively. The subordinator function with a positive correlation between a particular growth variable and drought tolerance was expressed by Eq. [1], whereas a negative correlation was expressed by Eq. [2].

2. Principal component analysis was used to extract the common factors associated with the cumulative variance contribution rate $(\geq 85 \%$ ). Common factor scores of different drought tolerance indicators were then calculated. With the variance contribution rate of the principal component as the weight, weighted summations of the extracted scores were conducted to obtain the coefficient of each indicator in a composite drought resistance score model. Finally, the coefficient of the composite score model was normalized to obtain the index weight $\left(W_{j}\right)$ of each indicator. Based on factor weight $W_{j}$ and the subordinative function $\mu\left(X_{i j}\right)$, the integrated evaluation index $D$ was calculated using Eq. [3].

$$
D_{i}=\sum \mu\left(X_{i j}\right) \times W_{j} \quad \text { for } j=1,2,3 \ldots \ldots n
$$

With the integrated evaluation index, the responses of different kiwifruit genotypes to drought stress were evaluated in a comprehensive and quantitative manner with a single value.

Statistical analysis. Data were analyzed for significant differences by analysis of variance using SPSS statistical software (version 16.0 for Windows; IBM Corp., Armonk, NY). Significant effects were determined using Fisher's least significant difference test $(P<0.05)$.

\section{Results}

Effects of PEG-Induced drought Stress on DDI. During the $30 \mathrm{~d}$ culture period, PEG-induced damage symptoms differed between PEG treatments, and the symptoms became more severe with increasing PEG concentrations in the five kiwifruit species. In general, the seedlings barely grew under 


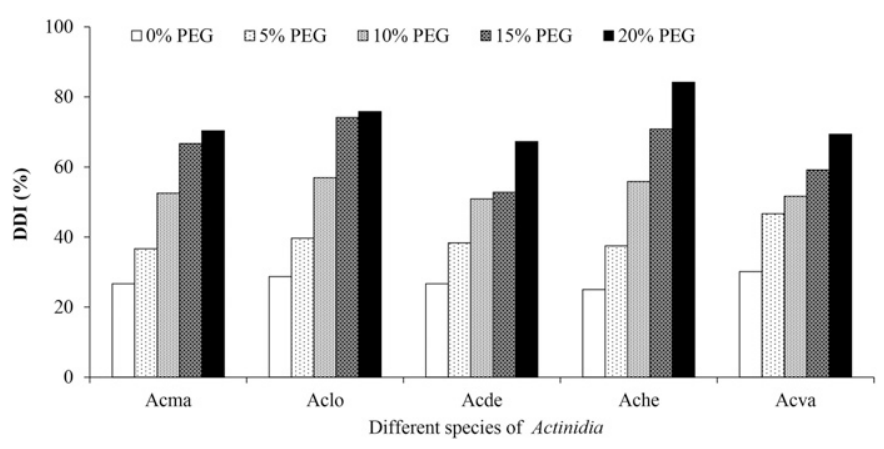

Fig. 2. Drought damage index (DDI) values of five Actinidia species under drought stress: Actinidia macrosperma (Acma), Actinidia longicarpa (Aclo), Actinidia deliciosa 'Hayward' (Acde), Actinidia hemsleyana (Ache), and Actinidia valvata (Acva). Sterile rootless plantlets, with two to three leaves and $\approx 1 \mathrm{~cm}$ height, of the five species were used in this study, and polyethylene glycol [PEG (formula weight 8000)] was added to the medium [Murashige and Skoog medium $+1.0 \mathrm{mg} \cdot \mathrm{L}^{-1}$ zeatin $+0.5 \mathrm{mg} \cdot \mathrm{L}^{-1}$ gibberellin $\left.\mathrm{A} 3(\mathrm{pH} \mathrm{5.8})\right]$ at different concentrations $(0 \%, 5 \%, 10 \%, 15 \%$, and $20 \%)$ to induce drought stress. After $30 \mathrm{~d}$ of treatment $\left(14 / 10 \mathrm{~h}\right.$ light/dark, 24 to $\left.26{ }^{\circ} \mathrm{C}\right)$, DDI values were calculated according to the designed grade scale. Each drought treatment of each kiwifruit species was repeated 30 times.

high PEG concentrations ( $>10 \%)$, leaves and shoots gradually wilted and dried with some leaf abscission and growth was inhibited. Under low PEG concentrations (5\% and 10\%), the leaves yellowed and withered, and the growth rate was slow compared with control in the five kiwifruit species. DDI values were calculated based on leaf and shoot symptoms using Eq. [1]. At a 5\% PEG concentration, the lowest DDI values were observed in Acma. At a 10\% PEG concentration, the DDI values in Acma, Acde, and Acva were lower than 55\% $(52.50 \%, 50.89 \%$, and $51.67 \%$, respectively). At a $15 \%$ PEG concentration, Acde had the minimum DDI value (52.78\%), whereas the DDI values of Acma, Acde, and Acva in media with $20 \%$ PEG were $70.37 \%, 67.24 \%$, and $69.35 \%$, respectively (Fig. 2). The results indicated that PEG-induced drought stress was harmful to kiwifruit, and the damage effects increased with increasing PEG concentrations.

EfFects of PEG-INDUCEd DROUGHT STRESS ON GROWTH INDICATORS. The FW of five Actinidia species decreased significantly under drought stress (Fig. 3A). Compared with the control, FW of five species decreased by more than $25 \%$ at a $5 \%$ PEG concentration and by more than $50 \%$ at $10 \%$ PEG concentration. The decrease in FW exceeded $60 \%$ and $70 \%$ at $15 \%$ and $20 \%$ PEG concentrations, respectively. The changes in PLH of five species varied (Fig. 3B). PLH at all four PEG concentrations decreased significantly in Aclo, Acde, and Ache as compared with that in the control. In Aclo, there was no significant difference in PLH between 5\%, 10\%, and 15\% PEG concentrations, but PLH further decreased at the 20\% PEG concentration. PLH of Acde, Acma, and Acva was not significantly different between the four PEG treatments. After
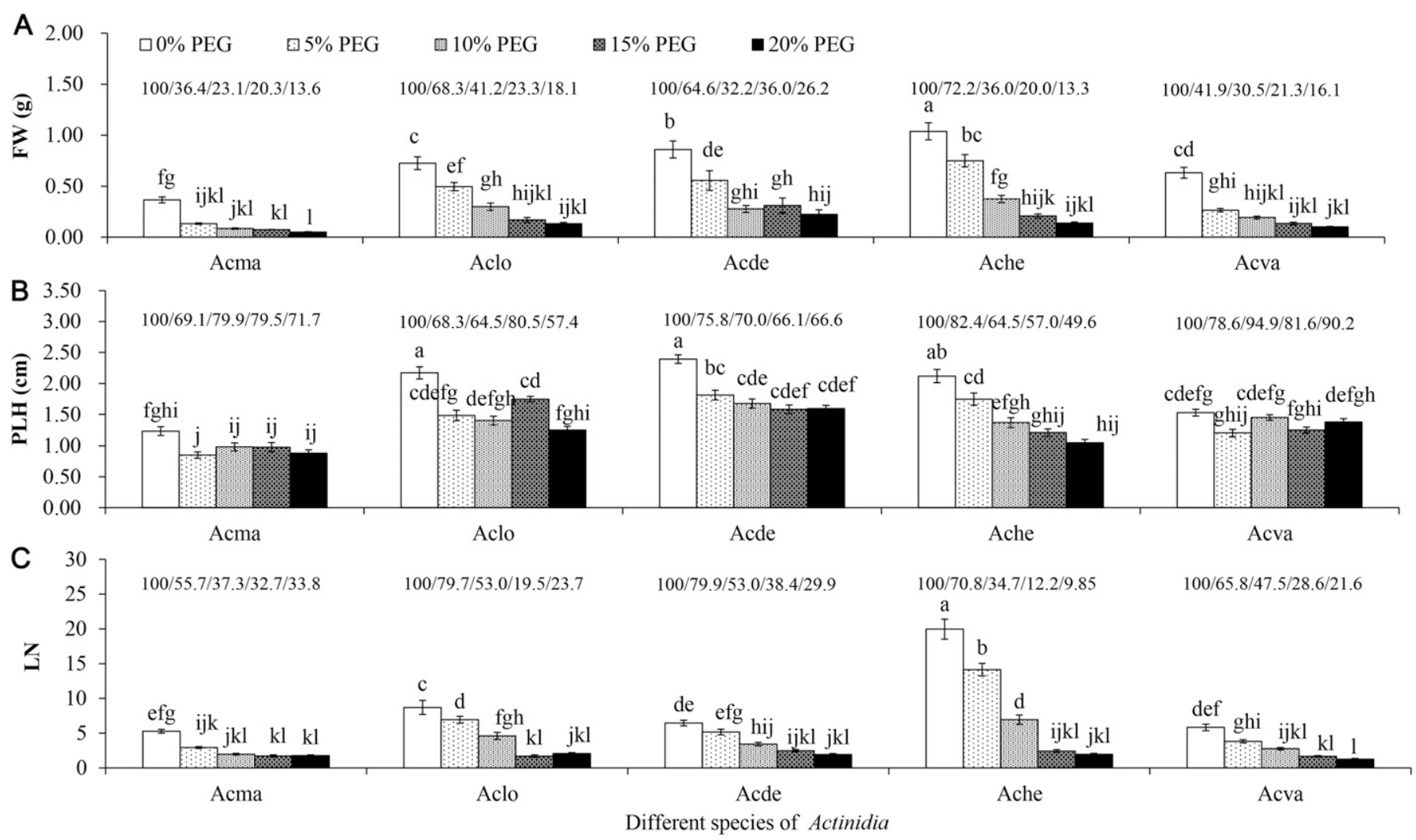

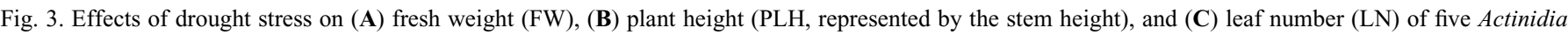
species: Actinidia macrosperma (Acma), Actinidia longicarpa (Aclo), Actinidia deliciosa 'Hayward' (Acde), Actinidia hemsleyana (Ache), and Actinidia valvata (Acva). Sterile rootless plantlets, with two to three leaves and $\approx 1 \mathrm{~cm}$ height, of the five species were used in this study, and polyethylene glycol [PEG (formula weight 8000$)$ ] was added to the medium [Murashige and Skoog medium $+1.0 \mathrm{mg} \cdot \mathrm{L}^{-1}$ zeatin $\left.+0.5 \mathrm{mg} \cdot \mathrm{L}^{-1} \mathrm{gibberellin} \mathrm{A3}(\mathrm{pH} 5.8)\right]$ at different concentrations $(0 \%$, $5 \%, 10 \%, 15 \%$, and 20\%) to induce drought stress. After $30 \mathrm{~d}$ of treatment (14/10 h light/dark, 24 to $\left.26^{\circ} \mathrm{C}\right)$, three growth indicators (FW, PLH, and LN) were measured. The numbers on the columns represent the percentages of four PEG treatments $(5 \%, 10 \%, 15 \%$, and $20 \%)$ compared with the control $(0 \%$ PEG, designed as $100 \%)$. Error bars indicate mean \pm SE $(n=30)$, and different letters indicate significant differences according to Fisher's least significant difference test $(P<0.05)$. 
the initial significant decrease at a 5\% PEG concentration, the PLH of Ache continued decreasing as the PEG concentration increased to $10 \%, 15 \%$, and $20 \%$. LN of the five species decreased with increasing PEG concentrations (Fig. 3C). In Ache, which had the highest LN at $0 \%$ and 5\% PEG concentrations, LN decreased sharply when the PEG concentration exceeded $10 \%$. In the other four species, LN remained at the same level after the initial decrease. Of the three growth indicators, PLH varied the most among the five kiwifruit species under drought stress.

EFFects of PEG-INDUCED DROUGHT STRESS ON ANTIOXIDANT ENZYME ACTIVITIES. The SOD activities of Acma, Aclo, and Ache first increased and then decreased. However, in Acde and Acva, SOD activity followed a slight increasing trend, although some of the changes were not significant (Fig. 4A). The drought stress intensity differed when SOD activity in the five species reached its maximum level at different drought stress intensities. Thus, in Acma and Acva, SOD activity peaked at a 15\% PEG concentration, whereas it peaked at $10 \%$ PEG in Aclo and Ache and at 20\% PEG in Acde. SOD activity in Ache remained high as the PEG concentration increased to $>5 \%$. POX activity

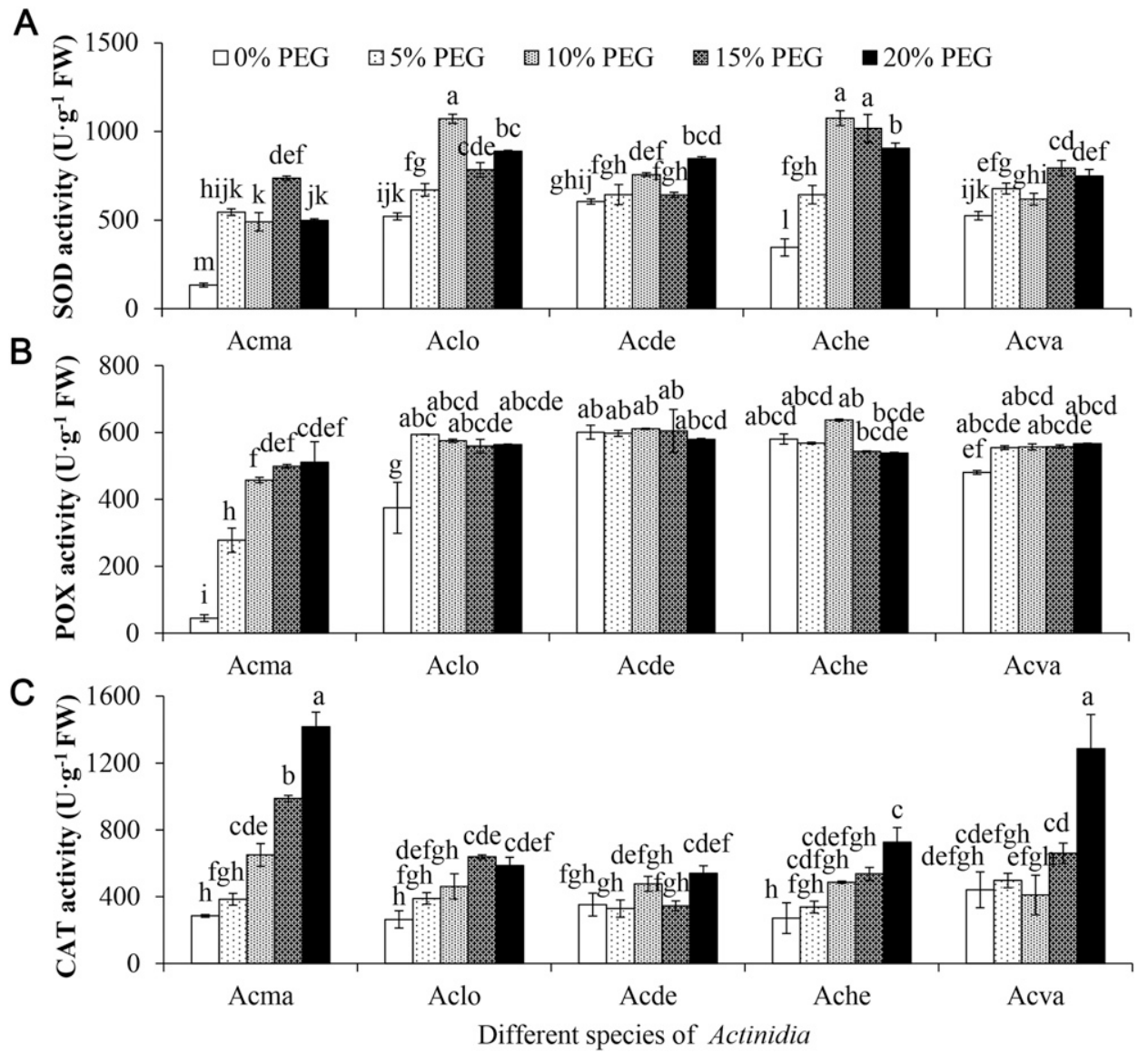

Fig. 4. Effects of drought stress on the activities of (A) superoxide dismutase (SOD), (B) peroxidase (POX), and (C) catalase (CAT) of five Actinidia species: Actinidia macrosperma (Acma), Actinidia longicarpa (Aclo), Actinidia deliciosa 'Hayward' (Acde), Actinidia hemsleyana (Ache), and Actinidia valvata (Acva). Sterile rootless plantlets, with two to three leaves and $\approx 1 \mathrm{~cm}$ height, of the five species were used in this study, and polyethylene glycol [PEG (formula weight 8000 )] was added to the medium [Murashige and Skoog medium + $1.0 \mathrm{mg} \cdot \mathrm{L}^{-1}$ zeatin $+0.5 \mathrm{mg} \cdot \mathrm{L}^{-1}$ gibberellin $\left.\mathrm{A} 3(\mathrm{pH} 5.8)\right]$ at different concentrations $(0 \%, 5 \%, 10 \%, 15 \%$, and $20 \%)$ to induce drought stress. After $30 \mathrm{~d}$ of treatment (14/10 h light/dark, 24 to $\left.26{ }^{\circ} \mathrm{C}\right)$, activities of three antioxidant enzymes (SOD, POX, and CAT) were measured. Error bars indicate mean $\pm \operatorname{SE}(n=3)$, and different letters indicate significant differences between treatments according to Fisher's least significant difference test $(P<0.05) . \mathrm{FW}=$ fresh weight. increased with increasing PEG concentrations in Acma but it was not significantly different between the control and the four PEG treatments in Acde and Ache. Moreover, POX activity were not significant (Fig. 4B). CAT activity increased dramatcally with increasing PEG concentration in Acma, and it was migher at the 20\% PEG concentration than in the other pared with those observed at lower concentrations in Aclo. However, CAT activity increased slightly in Ache with inPEG concentrations, but some of the changes were not slightly at 5\% and 15\% PEG concentrations, but it was not visibly different compared with the other three PEG treatments

EFFects of PEG-INDUCED DROUGHT STRESS ON OSMOTIC ADJUSTMENT SUBSTANCES. The SS content increased slightly in Acma, Aclo, Acde, and Ache, the increase was not significant in some cases. SS content in Acva decreased gradually with increasing PEG concentrations, with the exception of the $20 \%$ PEG concentration, and it was much higher than that observed in the other four species at the same PEG concentrations (Fig. 5A). Compared with the control, PRO contents were much higher in the four PEG treatments in Acma and Acva but the changes followed different trends. Compared with the control, PRO content in Aclo and Acde increased remarkably at $15 \%$ and $20 \%$ PEG concentrations. However, at the $10 \%$ PEG concentration, the increase was significant in Acde but not in Aclo. In Ache, PRO content increased significantly only at the 15\% PEG concentration compared with the control (Fig. 5B).

EFFects of PEG-INDUCED DROUGHT STRESS ON MDA CONTENTS. The MDA content in five species increased gradually, especially in Aclo but the increase was not always significant (Fig. 6). The MDA contents in Acma at 10\%, $15 \%$, and $20 \%$ PEG concentrations were not significantly different but the contents were higher than those measured in 5\% PEG and control treatments. In Aclo, MDA contents at $10 \%$ and $15 \%$ PEG concentrations were basically equal and higher than that of the control, and the contents further increased as the PEG concentration increased to $15 \%$ and $20 \%$. Compared with the control, the increased MDA contents in Acde at 5\% and 10\% PEG concentrations were not significant 

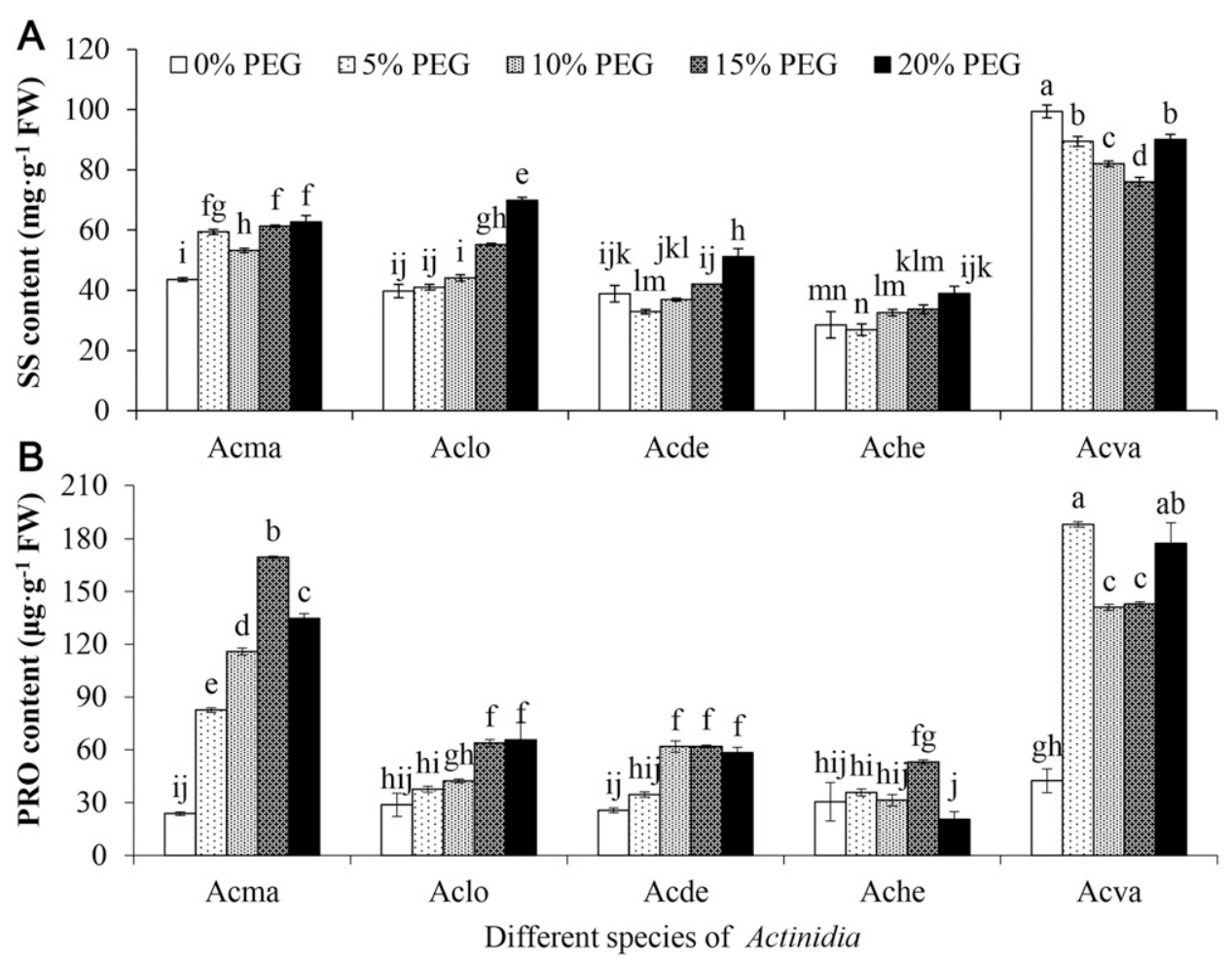

Fig. 5. Effects of drought stress on the contents of (A) soluble sugar (SS) and (B) proline (PRO) of five Actinidia species: Actinidia macrosperma (Acma), Actinidia longicarpa (Aclo), Actinidia deliciosa 'Hayward' (Acde), Actinidia hemsleyana (Ache), and Actinidia valvata (Acva). Sterile rootless plantlets, with two to three leaves and $\approx 1 \mathrm{~cm}$ height, of the five species were used in this study, and polyethylene glycol [PEG (formula weight 8000)] was added to the medium [Murashige and Skoog medium $+1.0 \mathrm{mg} \cdot \mathrm{L}^{-1}$ zeatin $+0.5 \mathrm{mg} \cdot \mathrm{L}^{-1}$ gibberellin A3 (pH 5.8)] at different concentrations $(0 \%, 5 \%, 10 \%, 15 \%$, and $20 \%)$ to induce drought stress. After $30 \mathrm{~d}$ of treatment (14/10 h light/dark, 24 to $26^{\circ} \mathrm{C}$ ), contents of two osmotic adjustment substances (SS and PRO) were measured. Error bars indicate mean $\pm \mathrm{SE}(n=3)$, and different letters indicated significant differences between treatments according to Fisher's least significant difference test $(P<0.05)$. FW $=$ fresh weight.
PEG concentration but it increased again with further increases in PEG concentrations, but MDA contents in plants at 5\%, 15\%, and 20\% PEG concentrations were not significantly different. In Acva, there was no significant difference between the control and the 5\% PEG concentration, and MDA contents measured at the other three PEG treatments increased significantly compared with the control.

PCA AND COMPREHENSIVE ASSESSMENT. Ten growth and physiological indicators were analyzed by PCA, and drought tolerance efficiency $(\alpha)$, which was calculated as the quotient of the mean of four PEG-induced drought treatments divided by the control, is listed in Supplemental Table 1. Four principal components were extracted according to the cumulative rate ( $\geq 85 \%$ ): the first principal component contained FW, PLH, LN, and DDI, representing the growth index; the second component comprised PRO, SS, and CAT, representing the osmotic adjustment substances, with the exception of CAT; the third component included SOD and POX, representing the antioxidant system; and MDA was assigned to the fourth component, representing products of membrane lipid peroxidation un-

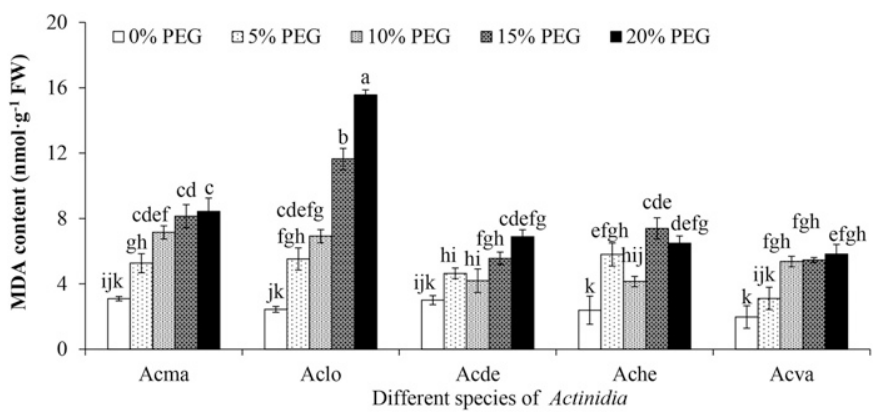

Fig. 6. Effects of drought stress on the malondialdehyde (MDA) content of five Actinidia species: Actinidia macrosperma (Acma), Actinidia longicarpa (Aclo), Actinidia deliciosa 'Hayward' (Acde), Actinidia hemsleyana (Ache), and Actinidia valvata (Acva). Sterile rootless plantlets, with two to three leaves and $\approx 1 \mathrm{~cm}$ height, of the five species were used in this study, and polyethylene glycol [PEG (formula weight 8000 )] was added to the medium [Murashige and Skoog medium $+1.0 \mathrm{mg} \cdot \mathrm{L}^{-1}$ zeatin $+0.5 \mathrm{mg} \cdot \mathrm{L}^{-1}$ gibberellin A3 (pH 5.8)] at different concentrations $(0 \%, 5 \%, 10 \%, 15 \%$, and $20 \%)$ to induce drought stress. After $30 \mathrm{~d}$ of treatment $\left(14 / 10 \mathrm{~h}\right.$ light/dark, 24 to $\left.26^{\circ} \mathrm{C}\right)$, MDA contents were measured. Error bars indicate mean $\pm \mathrm{SE}(n=3)$, and different letters indicate significant differences between treatments according to Fisher's least significant difference test $(P<0.05)$. FW $=$ fresh weight.

but it increased to significant levels at $15 \%$ and $20 \%$ PEG concentrations. MDA contents in Ache were higher at the four PEG concentrations compared with the control. After the initial increase, MDA contents in Ache decreased slightly at the $10 \%$ der drought stress. The contribution rates of the first four principle components were $45.546 \%, 19.342 \%, 11.268 \%$, and $9.683 \%$, respectively, and the cumulative rate was $85.840 \%$. The correlation analysis results indicated that DDI was negatively related to FW, PLH, and LN, and PRO was positively related to CAT and SS. Furthermore, SOD was also positively related to POX, and MDA had no significant correlation with other parameters, rendering MDA the only parameter associated with the fourth principal component (Table 1). Based on the comprehensive evaluation $(D)$ values of the five kiwifruit genotypes used in this study, the order of drought tolerance under tissue culture condition was as follows: Acma $>$ Acva $>$ Acde $>$ Aclo $>$ Ache (Table 2).

\section{Discussion}

Plants require sufficient water to maintain the normal growth, development, and reproduction, but they are often exposed to adverse environmental conditions because of their sessile nature. Drought stress is one of the major limitations to global agricultural production because of the complexity of the water-limiting environment and changing climate (Fang and Xiong, 2015). Plants have evolved a wide range of morphological, physiological, biochemical, and molecular changes to adapt to water deficit or drought stress conditions (Danquah et al., 2014). Drought stress severely restricted PLH, leaf dry weight, stem dry weight, node number, and root development 
Table 1. Correlation matrix of 10 indices under drought stress. Sterile rootless plantlets with two to three leaves and $\approx 1 \mathrm{~cm}$ height, of five Actinidia species were used in this study, and polyethylene glycol [PEG (formula weight 8000)] was added into the medium [Murashige and Skoog medium + $1.0 \mathrm{mg} \cdot \mathrm{L}^{-1}$ zeatin $+0.5 \mathrm{mg} \cdot \mathrm{L}^{-1}$ gibberellin A3 ( $\left.\mathrm{pH} \mathrm{5.8)}\right]$ with different concentrations $(0 \%, 5 \%$, $10 \%, 15 \%$, and $20 \%)$ to induce drought stress. After $30 \mathrm{~d}$ treatment $(14 / 10 \mathrm{~h} \mathrm{light} / \mathrm{dark}, 24$ to $\left.26{ }^{\circ} \mathrm{C}\right), 10$ indices were measured. Each PEG treatment of each species contained 30 plantlets.

\begin{tabular}{lllllllllll}
\hline Index & DDI & FW & PLH & LN & PRO & SOD & POX & CAT & MDA & SS \\
\hline DDI & 1.000 & & & & & & & & & \\
FW & $-0.779^{* *}$ & 1.000 & & & & & & & \\
PLH & $-0.525^{* *}$ & $0.823^{* *}$ & 1.000 & & & & & & & \\
LN & $-0.656^{* *}$ & $0.876^{* *}$ & $0.589^{* *}$ & 1.000 & & & & & & \\
PRO & $0.350^{*}$ & $-0.592^{* *}$ & $-0.501^{* *}$ & $-0.469^{* *}$ & 1.000 & & & & \\
SOD & $0.664^{* *}$ & $-0.359^{*}$ & -0.147 & $-0.351^{*}$ & 0.008 & 1.000 & & & & \\
POX & $0.348^{*}$ & 0.077 & 0.286 & 0.044 & 0.075 & $0.628^{* *}$ & 1.000 & & \\
CAT & $0.666^{* *}$ & $-0.619^{* *}$ & $-0.525^{* *}$ & $-0.501^{* *}$ & $0.634^{* *}$ & 0.174 & 0.134 & 1.000 & & \\
MDA & 0.104 & -0.174 & -0.063 & -0.139 & 0.270 & 0.081 & -0.083 & 0.059 & 1.000 & \\
SS & 0.188 & $-0.422^{*}$ & $-0.373^{*}$ & $-0.462^{*}$ & $0.711^{* *}$ & -0.059 & -0.062 & $0.421^{*}$ & 0.167 & 1.000 \\
\hline
\end{tabular}

**represented significant correlation $[P<0.01$ (two-tailed $t$ test)]; *represented significant correlation $[P<0.05$ (two-tailed $t$ test)].

$\mathrm{DDI}=$ drought damage index; FW = fresh weight; $\mathrm{PLH}=$ plant height (represented by the stem height); $\mathrm{LN}=$ leaves number; $\mathrm{PRO}=$ proline; $\mathrm{SOD}=$ superoxide dismutase; $\mathrm{POX}=$ peroxidase; $\mathrm{CAT}=$ catalase $; \mathrm{MDA}=$ malondialdehyde $; \mathrm{SS}=$ soluble sugar.

Table 2. Comprehensive evaluation of drought tolerance of five Actinidia species. Sterile rootless plantlets with two to three leaves and $\approx 1 \mathrm{~cm}$ height, of five Actinidia species were used in this study, and polyethylene glycol [PEG (formula weight 8000)] was added into the medium [Murashige and Skoog medium $+1.0 \mathrm{mg} \cdot \mathrm{L}^{-1}$ zeatin $+0.5 \mathrm{mg} \cdot \mathrm{L}^{-1}$ gibberellin $\mathrm{A} 3(\mathrm{pH} 5.8)$ ] with different concentrations $(0 \%, 5 \%, 10 \%, 15 \%$, and $20 \%)$ to induce drought stress. After $30 \mathrm{~d}$ treatment $\left(14 / 10 \mathrm{~h} \mathrm{light/dark,} 24\right.$ to $\left.26^{\circ} \mathrm{C}\right), 10$ indices were measured and the data were analyzed using principal component analysis.

\begin{tabular}{lcccccccccc}
\hline Species $^{\mathrm{z}}$ & CI $(1)^{\mathrm{y}}$ & CI (2) & CI (3) & CI (4) & $\mu(1)$ & $\mu(2)$ & $\mu(3)$ & $\mu(4)$ & $D$ & Rank \\
\hline Acma & 2.6364 & 5.0244 & 7.9131 & 1.5643 & 1.0000 & 1.0000 & 1.0000 & 0.4075 & 0.9332 & 1 \\
Aclo & 0.5219 & 1.9565 & 2.6957 & 0.1434 & 0.1509 & 0.2150 & 0.1389 & 0.0000 & 0.1467 & 4 \\
Acde & 0.6236 & 1.7799 & 1.8543 & 0.8957 & 0.1917 & 0.1698 & 0.0000 & 0.2158 & 0.1643 & 3 \\
Ache & 0.1462 & 1.1163 & 2.4388 & 2.2663 & 0.0000 & 0.0000 & 0.0965 & 0.6089 & 0.0813 & 5 \\
Acva & 0.9254 & 2.5142 & 2.0338 & 3.6299 & 0.3129 & 0.3577 & 0.0296 & 1.0000 & 0.3633 & 2 \\
Contribution & 45.564 & 19.342 & 11.268 & 9.683 & & & & & & \\
$\quad$ rate (\%) & & & & & & & & & \\
Index weight & & & & & 0.5307 & 0.2253 & 0.1312 & 0.1128 &
\end{tabular}

${ }^{\mathrm{z}}$ Acma $=$ Actinidia macrosperma $;$ Aclo = Actinidia longicarpa $;$ Acde $=$ Actinidia deliciosa 'Hayward'; Ache = Actinidia hemsleyana , Acva = Actinidia valvata .

${ }^{\mathrm{y}} \mathrm{CI}=$ comprehensive index; $\mu(x)=$ subordinative function; $D=$ comprehensive evaluation value.

in cotton (Pace et al., 1999); decreased tuber dry weight and total biomass in jerusalem artichoke [Helianthus tuberosus (Ruttanaprasert et al., 2016)]; and reduced pod yield and total biomass of peanut [Arachis hypogaea (Pereira et al., 2016)]. In this study, three growth indicators, FW, PLH, and LN decreased with increasing PEG concentrations (Fig. 3). As a comprehensive index, the DDI values of five kiwifruit species also increased, indicating the damaging effects of PEG-induced drought stress (Figs. 1 and 2). The same phenomenon was also reported for soybean (Glycine max), where drought stress caused severe wilting and discoloration of leaves in a sensitive genotype but relatively less damage in a resistant genotype (Liu et al., 2017a). Other types of environmental stress (e.g., salt stress) also inhibit the growth of kiwifruit. A previous study indicated that shoot height as well as the shoot, leaf, and root dry weights of 'Hayward' (A. deliciosa) were reduced with $\mathrm{Na} / \mathrm{Cl}$ application, and $\mathrm{Cl}$ and $\mathrm{Na}$ concentrations in shoots, leaves, and roots generally increased with increasing $\mathrm{Cl}$ and $\mathrm{Na}$ application (Cangi and Tarakcioglu, 2006). In $A$. arguta, PLH, root length, and hypocotyl length also decreased with increasing $\mathrm{NaCl}$ concentration stress (Liu et al., 2017b)

Drought stress usually leads to high amounts of reactive oxygen species (ROS), especially the hydroxyl radical and single oxygen $\left({ }^{1} \mathrm{O}_{2}\right)$ (both of which are very reactive), causing oxidative damage to many cell components (Cruz de Carvalho, 2008). Antioxidant enzymes play important roles in ROS scavenging, and the activation of these enzymes was found to be a common response among plant species to drought stress, suggesting that a higher antioxidant capacity was associated with the tolerance of plants to stress (Wang et al., 2014; Zandalinas et al., 2017). In this study, SOD and CAT activities increased at different degrees in five kiwifruit species under PEGinduced drought stress, especially SOD activities in Aclo and Ache (Fig. 4A) and the CAT activities in Acma and Acva (Fig. 4C). The POX activities showed slight fluctuations, and significant changes were only observed in some PEG treatments (Fig. 4B). Moreover, when exogenous abscisic acid was applied to 2-year-old potted $A$. deliciosa plants, the activities of SOD, POX, and CAT enhanced and improved drought tolerance (Wang et al., 2010). Under $\mathrm{NaCl}$ stress, POX and SOD activities of $A$. arguta increased but CAT activity decreased with increasing $\mathrm{NaCl}$ concentration stress (Liu et al., 2017b). The results showed the different effects of enzymatic components on ROS scavenging processes in kiwifruit species, and the antioxidant enzyme activities in a drought-tolerant cotton cultivar were significantly increased compared with those in a drought-sensitive cultivar (Zhang et al., 2014). However, in wheat (Triticum aestivum) lines, CAT activity remained constant or decreased under drought stress, so no relationship was found between enzyme activity and drought tolerance (Sharifi et al., 2012). These results highlighted the specificity of antioxidant enzyme activities in different species or cultivars. Oxidative damage caused by ROS under drought stress usually resulted in cell membrane lipid peroxidation and the production of high amounts of MDA. Similar to the results reported in olive (Olea europaea) and tomato (Solanum lycopersicum) plants (Petridis et al., 2012; SanchezRodriguez et al., 2010), the MDA contents of the five species increased under PEG-induced drought stress, especially in Aclo (Fig. 6). Furthermore, MDA contents in A. arguta also 
increased with increasing $\mathrm{NaCl}$ concentration stress (Liu et al., 2017b)

Plants produce and accumulate several types of osmolytes, including PRO, SS, glycine betaine, and mannitol, to avoid negative effects of water decline, which strongly correlated with tolerance to drought stress (Hoekstra et al., 2001). SS, as the primary product of photosynthesis in plants, was involved in osmoregulation at the cellular level as well as the maintenance of water potential and cellular turgor functions (Blum, 2017; Kanai et al., 2007). In this study, SS contents in four kiwifruit species (Acma, Aclo, Acde, and Ache) increased significantly under drought stress but its contents in Acva decreased significantly (Fig. 5A). In another study, SS content significantly decreased in the summer, and the reason might be increased translocation associated with plant growth (Savé et al., 1994). Decreased SS contents under drought stress were also reported in cotton leaves (Pline et al., 2003). Therefore, the trend of increased SS might result from the requirement of increased energy supplies and signal molecules in plants required to maintain growth under adverse environmental conditions such as drought stress, which inhibits photosynthesis and the translocation of assimilates (Thalmann and Santelia, 2017). Sucrose, as the primary component of SS (Xiao et al., 2017), is not only the source of hexoses, which are necessary for energy generation and antioxidant compound synthesis as a part of abiotic stress responses, but also acts as a signal molecule that regulates the expression of microRNAs, transcription factors, and genes. Furthermore, it participates in the crosstalk between hormonal, oxidative, and defense signaling (Ruan, 2014; Tognetti et al., 2013).

In addition to being an osmolyte, PRO also acted as a ROS scavenger and a molecular chaperone, stabilizing the structure of proteins, thereby protecting the cells from damage caused by adverse environments (Krasensky and Jonak, 2012). Therefore, genotypes with higher PRO content could be more resistant to stress conditions, as reported in different pistachio (Pistacia vera) and wheat genotypes (Khoyerdi et al., 2016). Moreover, PRO content was positively correlated with grain yield under drought stress conditions, and it was considered a good indicator of drought tolerance in wheat, which could be useful during genotype selection (Mwadzingeni et al., 2016). Leaf PRO contents of Acma and Acva were much higher compared with those of the other three kiwifruit species under drought stress (Fig. 5B).

The PCA method has been used to analyze huge amounts of data and excavate valuable information, and the analytic result provided help for screening tolerant germplasm resources in crop improving programs (Fleta-Soriano and Munne-Bosch, 2016; Mahajan et al., 2013; Noreen and Ashraf, 2009; Ullah et al., 2017; Wang et al., 2013). A comprehensive system that included morphological, physiological, and biochemical components should be established for the precise assessment of stress tolerance in crops. Based on 10 growth, physiological, and biochemical indicators (FW, PLH, LN, DDI, SOD, POX, CAT, SS, PRO, and MDA), the genotypes of $A$. macrosperma and $A$. valvata used in this study were more resilient germplasm resources in the five examined kiwifruit species. According to the results, PCA, DDI, FW, PLH, and LN constituted the first principal component, and DDI was negatively related to FW, PLH, and LN. Furthermore, these four parameters represented growth indicators, and the contribution rate was $45.546 \%$. These results suggested drought tolerance evaluations in kiwifruit should be mainly focused on morphological characteristics and growth parameters, and these results could help us quickly and effectively screen resistant germplasm resources in future studies. Another important thing was the relevance between tissue culture evaluation and field performance. Previous studies showed the consistency of the drought tolerance of apple (Malus sieversii) rootstocks under tissue culture (PEG 6000) and the hydroponic conditions of apple (Tan, 2007; Zhang et al., 2013). The same results were also found when examining the drought tolerance of potato (Solanum tuberosum) cultivars Haoyuan 7 and Bashu 10 under tissue culture (PEG 8000) and field conditions (controlled soil moisture content) (Deng et al., 2014; Xu et al., 2011). Therefore, the two genotypes of $A$. macrosperma and $A$. valvata used in this study might be promising materials that could accelerate the process of drought tolerance in kiwifruit breeding (cultivar or rootstock). The results of this study also provided some evidence that could potentially guide parent selection in kiwifruit-breeding programs.

\section{Literature Cited}

Barnabas, B., K. Jager, and A. Feher. 2008. The effect of drought and heat stress on reproductive processes in cereals. Plant Cell Environ. 31:11-38.

Bates, L.S., R.P. Waldren, and I.D. Teare. 1973. Rapid determination of free proline for water-stress studies. Plant Soil 39:205-207.

Blum, A. 2017. Osmotic adjustment is a prime drought stress adaptive engine in support of plant production. Plant Cell Environ. 40:4-10.

Cakmak, I. and H. Marschner. 1992. Magnesium deficiency and high light intensity enhance activities of superoxide dismutase, ascorbate peroxidase, and glutathione reductase in bean Phaseolus vulgaris leaves. Plant Physiol. 98:1222-1227.

Cangi, R. and C. Tarakcioglu. 2006. Effect of sodium and chloride ions toxicity on growth and mineral contents of kiwifruit plant. Asian J. Chem. 18(3):1-6.

Ciais, P., M. Reichstein, N. Viovy, A. Granier, J. Ogee, V. Allard, M. Aubinet, N. Buchmann, C. Bernhofer, A. Carrara, F. Chevallier, N. De Noblet, A.D. Friend, P. Friedlingstein, T. Grunwald, B. Heinesch, P. Keronen, A. Knohl, G. Krinner, D. Loustau, G. Manca, G. Matteucci, F. Miglietta, J.M. Ourcival, D. Papale, K. Pilegaard, S. Rambal, G. Seufert, J.F. Soussana, M.J. Sanz, E.D. Schulze, T. Vesala, and R. Valentini. 2005. Europe-wide reduction in primary productivity caused by the heat and drought in 2003. Nature 437:529-533.

Cruz-Castillo, J.G., G.S. Lawes, and D.J. Woolley. 1997. The influence of rootstock and 'Hayward' scion selection on fruit firmness and soluble solids. Acta Hort. 444:513-516.

Cruz-Castillo, J.G., G.S. Lawes, D.J. Woolley, and H. Varela-Alvarez. 1991. Rootstock influence on kiwifruit vine performance. N. Z. J. Crop Hort. Sci. 19:361-364.

Cruz de Carvalho, M.H. 2008. Drought stress and reactive oxygen species: Production, scavenging and signaling. Plant Signal. Behav. 3:156-165.

Danquah, A., A. De Zelicourt, J. Colcombet, and H. Hirt. 2014. The role of ABA and MAPK signaling pathways in plant abiotic stress responses. Biotechnol. Adv. 32:40-52.

Deng, Z., J.F. Xu, S.G. Duan, J. Liu, C.S. Bian, W.F. Pang, and L.P. Jin. 2014. Effect on growth indicators of 11 potato cultivars in vitro under PEG-8000 stress. Acta Agr. Boreali Sin. 29(5):99-106 (in Chinese).

Fang, Y.J. and L.Z. Xiong. 2015. General mechanisms of drought response and their application in drought resistance improvement in plants. Cell. Mol. Life Sci. 72:673-689.

Ferguson, A.R. and H. Huang. 2007. Genetic resources of kiwifruit: Domestication and breeding. Hort. Rev. 33:1-122.

Fleta-Soriano, E. and S. Munne-Bosch. 2016. Stress memory and the inevitable effects of drought: A physiological perspective. Front. Plant Sci. 7:1-6.

Gallego, P.P., A. Martinez, and I. Zarra. 1997. Analysis of the growth kinetic of fruits of Actinidia deliciosa. Biol. Plant. 39:615-622. 
Giannopolitis, C.N. and S.K. Ries. 1977. Superoxide dismutases. 1 Occurrence in higher plants. Plant Physiol. 59:309-314.

Gopal, J. and K. Iwama. 2007. In vitro screening of potato against water-stress mediated through sorbitol and polyethylene glycol. Plant Cell Rpt. 26:693-700.

Hawken, T. 2013. Kiwifruit rootstocks for the future: World class orchard to market. EastPack Prunings 130:4-5.

Hoekstra, F.A., E.A. Golovina, and J. Buitink. 2001. Mechanisms of plant desiccation tolerance. Trends Plant Sci. 6:431-438.

Kanai, M., K. Higuchi, T. Hagihara, T. Konishi, T. Ishii, N. Fujita, Y. Nakamura, Y. Maeda, M. Yoshiba, and T. Tadano. 2007. Common reed produces starch granules at the shoot base in response to salt stress. New Phytol. 176:572-580.

Khoyerdi, F.F., M.H. Shamshiri, and A. Estaji. 2016. Changes in some physiological and osmotic parameters of several pistachio genotypes under drought stress. Scientia Hort. 198:44-51.

Krasensky, J. and C. Jonak. 2012. Drought, salt, and temperature stress-induced metabolic rearrangements and regulatory networks. J. Expt. Bot. 63:1593-1608.

Li, D., Y. Liu, X. Li, J. Rao, X. Yao, and C. Zhong. 2014. Genetic diversity in kiwifruit polyploid complexes: Insights into cultivar evaluation, conservation, and utilization. Tree Genet. Genomes 10:1451-1463.

Li, M.H., W.F. Xiao, P.L. Shi, S.G. Wang, Y.D. Zhong, X.L. Liu, X.D. Wang, X.H. Cai, and Z.M. Shi. 2008. Nitrogen and carbon sourcesink relationships in trees at the Himalayan treelines compared with lower elevations. Plant Cell Environ. 31:1377-1387.

Liu, D., C. Xin, R.H. Li, and X.F. Sunday. 2017b. Effect of NaCl stress on growth of Actinidia arguta seedling. North. Hort. 7:31-35 (in Chinese)

Liu, H.R., G.W. Sun, L.J. Dong, L.Q. Yang, S.N. Yu, S.L. Zhang, and J.F. Liu. 2017a. Physiological and molecular responses to drought and salinity in soybean. Biol. Plant. 61:557-564.

Luo, L.J. 2010. Breeding for water-saving and drought-resistance rice (WDR) in China. J. Expt. Bot. 61:3509-3517.

Mahajan, S.T., R.M. Naik, and U.S. Dalvi. 2013. Assessment of biochemical markers in differentiating sugarcane genotypes for salt tolerance. Sugar Tech 15:116-121.

Manavalan, L.P., S.K. Guttikonda, L.S.P. Tran, and H.T. Nguyen. 2009. Physiological and molecular approaches to improve drought resistance in soybean. Plant Cell Physiol. 50:1260-1276.

Mwadzingeni, L., H. Shimelis, S. Tesfay, and T.J. Tsilo. 2016. Screening of bread wheat genotypes for drought tolerance using phenotypic and proline analyses. Front. Plant Sci. 7:1-12.

Noreen, Z. and M. Ashraf. 2009. Assessment of variation in antioxidative defense system in salt-treated pea (Pisum sativum) cultivars and its putative use as salinity tolerance markers. J. Plant Physiol. 166:1764-1774.

Pace, P.F., H.T. Cralle, J.T. Cothren, and S.A. Senseman. 1999. Photosynthate and dry matter partitioning in short- and long-season cotton cultivars. Crop Sci. 39:1065-1069.

Pereira, J.W.D., M.B. Albuquerque, P.A. Melo, R. Nogueira, L.M. De Lima, and R.C. Santos. 2016. Assessment of drought tolerance of peanut cultivars based on physiological and yield traits in a semiarid environment. Agr. Water Mgt. 166:70-76.

Petridis, A., I. Therios, G. Samouris, S. Koundouras, and A. Giannakoula. 2012. Effect of water deficit on leaf phenolic composition, gas exchange, oxidative damage and antioxidant activity of four Greek olive (Olea europaea L.) cultivars. Plant Physiol. Biochem. 60:1-11.

Pline, W.A., R. Wells, G. Little, K.L. Edmisten, and J.W. Wilcut. 2003. Glyphosate and water-stress effects on fruiting and carbohydrates in glyphosate-resistant cotton. Crop Sci. 43:879-885.

Ruan, Y.L. 2014. Sucrose metabolism: Gateway to diverse carbon use and sugar signaling. Annu. Rev. Plant Biol. 65:33-67.

Ruttanaprasert, R., S. Jogloy, N. Vorasoot, T. Kesmala, R.S. Kanwar, C.C. Holbrook, and A. Patanothai. 2016. Effects of water stress on total biomass, tuber yield, harvest index and water use efficiency in Jerusalem artichoke. Agr. Water Mgt. 166:130-138.

Salinger, M. 2005. Climate variability and change: Past, present and future: An overview. Clim. Change 70:9-29.
Sanchez-Rodriguez, E., M. Rubio-Wilhelmi, L.M. Cervilla, B. Blasco, J. J. Rios, M.A. Rosales, L. Romero, and J.M. Ruiz. 2010. Genotypic differences in some physiological parameters symptomatic for oxidative stress under moderate drought in tomato plants. Plant Sci. 178:30-40.

Savé, R., C. Olivella, C. Biel, J. Adillón, and R. Rabella. 1994. Seasonal patterns of water relationships, photosynthetic pigments and morphology of Actinidia deliciosa plants of the Hayward and Tomuri cultivars. Agronomie 14:121-126.

Shah, K., R.G. Kumar, S. Verma, and R.S. Dubey. 2001. Effect of cadmium on lipid peroxidation, superoxide anion generation and activities of antioxidant enzymes in growing rice seedlings. Plant Sci. $161: 1135-1144$

Sharifi, P., R. Amirnia, E. Majidi, H. Hadi, M. Roustaii, B. Nakhoda, H. M. Alipoor, and F. Moradi. 2012. Relationship between drought stress and some antioxidant enzymes with cell membrane and chlorophyll stability in wheat lines. Afr. J. Microbiol. Res. 6:617-623.

Tan, D.M. 2007. The physiology and biochemistry of programmed Malus siversii and M. hupehensis cell death under drought stress. Scientia Agr. Sin. 40:980-986 (in Chinese).

Thalmann, M. and D. Santelia. 2017. Starch as a determinant of plant fitness under abiotic stress. New Phytol. 214:943-951.

Tognetti, J.A., H.G. Pontis, and G.M.A. Martinez-Noel. 2013. Sucrose signaling in plants: A world yet to be explored. Plant Signal. Behav. 8:e23316.

Torres-Ruiz, J.M., G.D. Perulli, L. Manfrini, M. Zibordi, G.L. Velasco, S. Anconelli, E. Pierpaoli, L. Corelli-Grappadelli, and B. Morandi. 2016. Time of irrigation affects vine water relations and the daily patterns of leaf gas exchanges and vascular flows to kiwifruit (Actinidia deliciosa Chev.). Agr. Water Mgt. 166:101-110.

Tramontini, S., M. Vitali, L. Centioni, A. Schubert, and C. Lovisolo. 2013. Rootstock control of scion response to water stress in grapevine. Environ. Expt. Bot. 93:20-26.

Ullah, A., H. Sun, X. Yang, and X. Zhang. 2017. Drought coping strategies in cotton: Increased crop per drop. Plant Biotechnol. J. 15:271-284.

Wang, L., J.L. Zhang, D. Wang, J.W. Zhang, Y.S. Cui, Y.H. Liu, H.Y. Yang, and Y. Bin. 2013. Assessment of salt tolerance in transgenic potato carrying AtNHX1 gene. Crop Sci. 53:2643-2651.

Wang, X., M. Vignjevic, D. Jiang, S. Jacobsen, and B. Wollenweber. 2014. Improved tolerance to drought stress after anthesis due to priming before anthesis in wheat (Triticum aestivum L.) var. Vinjett. J. Expt. Bot. 65:6441-6456.

Wang, Y.L., F.W. Ma, M.J. Liu, L. Dong, and J. Zou. 2010. Physiological responses of kiwifruit plants to exogenous ABA under drought conditions. Plant Growth Regulat. 64:63-74.

Wang, Z.Y., K.J. Patterson, K.S. Gould, and R.G. Lowe. 1994. Rootstock effects on budburst and flowering in kiwifruit. Scientia Hort. 57:187-199.

Xiao, W.J., S. Hu, X.X. Zhou, R.Y. Yao, J.R. Luo, C.Y. Yuan, H.P. Chang, C. Zhang, J. Huang, J.Y. Li, S.C. Liu, M.L. Li, and X.H. Guo. 2017. A glucuronokinase gene in Arabidopsis, AtGlcAK, is involved in drought tolerance by modulating sugar metabolism. Plant Mol. Biol. Rptr. 35:298-311.

Xu, J.F., J. Liu, C.S. Bian, S.G. Duan, W.F. Pang, and L.P. Jin. 2011. Evaluation of drought tolerance in potato germplasm. Chin. Potato J. 25(1):1-6 (in Chinese).

Zandalinas, S.I., R. Mittler, D. Balfagón, V. Arbona, and A. GómezCadenas. 2017. Plant adaptations to the combination of drought and high temperatures. Physiol. Plant. 162:2-12.

Zeppel, M.J.B., S.P. Harrison, H.D. Adams, D.I. Kelley, G. Li, D.T. Tissue, T.E. Dawson, R. Fensham, B.E. Medlyn, A. Palmer, A.G. West, and N.G. McDowell. 2015. Drought and resprouting plants. New Phytol. 206:583-589.

Zhang, J., L.M. Zhao, and Z.R. Zhou. 2013. Drought resistance of different apple rootstocks in vitro. J. Fruit Sci. 30(1):88-93 (in Chinese). Zhang, L., J. Peng, T.T. Chen, X.H. Zhao, S.P. Zhang, S.D. Liu, H.L. Dong, L. Feng, and S.X. Yu. 2014. Effect of drought stress on lipid peroxidation and proline content in cotton roots. J. Anim. Plant Sci. 24:1729-1736. 
Supplemental Table 1. Drought tolerance efficiency $(\alpha)^{\mathrm{z}}$ of five Actinidia species under drought stress. Sterile rootless plantlets with two to three leaves and $\approx 1 \mathrm{~cm}$ height, of five Actinidia species were used in this study, and polyethylene glycol [PEG (formula weight 8000 )] was added into the Murashige and Skoog medium $+1.0 \mathrm{mg} \cdot \mathrm{L}^{-1}$ zeatin $+0.5 \mathrm{mg} \cdot \mathrm{L}^{-1}$ gibberellin A $\left.3(\mathrm{pH} 5.8)\right]$ with different concentrations $(0 \%, 5 \%, 10 \%$, $15 \%$, and $20 \%$ ) to induce drought stress. After $30 \mathrm{~d}$ treatment $\left(14 / 10 \mathrm{~h}\right.$ light/dark, 24 to $\left.26^{\circ} \mathrm{C}\right), 10$ indices were measured and drought tolerance efficiency of each species of each index were calculated.

\begin{tabular}{|c|c|c|c|c|c|}
\hline Indicators & $\mathrm{Acma}^{\mathrm{y}}$ & Aclo & Acde & Ache & Acva \\
\hline DDI & 2.1207 & 2.1478 & 1.9617 & 2.4833 & 1.8797 \\
\hline PLH & 0.7505 & 0.6769 & 0.6960 & 0.6337 & 0.8631 \\
\hline SOD & 4.2622 & 1.6411 & 1.1940 & 2.6327 & 1.3534 \\
\hline POX & 9.6727 & 1.5295 & 1.1940 & 0.9850 & 1.1629 \\
\hline CAT & 3.0116 & 1.9667 & 1.1984 & 1.9232 & 1.6145 \\
\hline MDA & 2.3462 & 0.4260 & 1.0580 & 2.4933 & 3.8840 \\
\hline
\end{tabular}

${ }^{\mathrm{z}}$ Drought tolerance efficiency $(\alpha)$ was the quotient of the mean of four drought treatments $(5 \%, 10 \%, 15 \%$, and $20 \%$ PEG) divided by the control (0\% PEG).

${ }^{\mathrm{y}}$ Acma $=$ Actinidia macrosperma $;$ Aclo = Actinidia longicarpa $;$ Acde = Actinidia deliciosa 'Hayward'; Ache = Actinidia hemsleyana; Acva = Actinidia valvata.

$\mathrm{DDI}=$ drought damage index; FW = fresh weight; PLH = plant height (represented the stem height); $\mathrm{LN}=$ leaves number; $\mathrm{SOD}=$ superoxide dismutase; $\mathrm{POX}=$ peroxidase $; \mathrm{CAT}=$ catalase $; \mathrm{SS}=$ soluble sugar; $\mathrm{PRO}=$ proline; $\mathrm{MDA}=$ malondialdehyde. 